\title{
POSTERIOR CRANIAL FOSSA LESIONS- A CLINICOPATHOLOGICAL CORRELATIVE STUDY
}

\author{
Priya V. S1, Surupa Susan Kurien²
}

${ }^{1}$ Assistant Professor, Department of Pathology, Government Medical College, Trivandrum, Kerala. ${ }^{2}$ Assistant Professor, Department of Pathology, Government Medical College, Trivandrum, Kerala.

\section{ABSTRACT}

\section{BACKGROUND}

Posterior cranial fossa houses the cerebellum and brainstem that contains all cranial nerve nuclei and many afferent fibre tracts that connect the brain with the rest of the body. Early diagnosis of posterior fossa lesions is vital to prevent complications like herniation and brainstem compression that is invariably fatal.

The present study is an attempt to collect the demographic profile and types of posterior fossa lesions. We also assessed the extent of correlation between clinical and radiological diagnosis and the diagnosis on histopathology.

\section{MATERIALS AND METHODS}

A retrospective analysis of 75 biopsy specimens from posterior fossa lesions received in the Department of Pathology, Government Medical College, Trivandrum, over a 3-year period was done. The data collected included age, sex, site of lesion, clinical presentation, radiological and histopathological diagnosis. The diagnosis in all the cases were made on haematoxylin and eosin stained slides of processed tissue.

\section{RESULTS}

We received a total of 75 cases of posterior fossa lesions in the 3-year period. Most of the lesions occurred in the age group between 50 and 59 years (20\%) followed by 0 to 9 years $(16 \%)$. The male-to-female ratio observed was 1.33: 1 . The nonneoplastic lesions observed were cerebellar abscess and arachnoid cyst. In adults, the most common tumour was Schwannoma, while in children it was medulloblastoma. Agreement between clinical and histopathological diagnosis was observed in $64 \%$ of the cases.

\section{CONCLUSION}

Posterior fossa lesions affect all age groups, especially paediatric age group with a male predominance. Clinical pathological correlation and grading are significant pertaining to the choice of treatment modality for the patient.

\section{KEYWORDS}

Posterior Fossa Lesions, Cerebellar Abscess, Arachnoid Cyst, Schwannoma, Meningioma.

HOW TO CITE THIS ARTICLE: Priya VS, Kurien SS. Posterior cranial fossa lesions- a clinicopathological correlative study. J. Evolution Med. Dent. Sci. 2017;6(64):4666-4669, DOI: 10.14260/Jemds/2017/1009

\section{BACKGROUND}

Posterior cranial fossa houses the brainstem and cerebellum. Brain stem contains all cranial nerve nuclei and many afferent fibre tracts that connect the brain with the rest of the body. Cerebellum is the major organ of co-ordination for all motor functions. ${ }^{1}$

A wide array of disease process can occur in the posterior cranial fossa. These include tumours arising from the brain tissue itself, the cranial nerves, the meninges or even the skull.

Magnetic resonance imaging is ideal for delineating posterior fossa and its lesions. In spite of the rapid advancement in radiology, histopathology still remains the gold standard in diagnosing space occupying lesions of the brain.

Financial or Other, Competing Interest: None.

Submission 11-07-2017, Peer Review 01-08-2017,

Acceptance 04-08-2017, Published 10-08-2017.

Corresponding Author:

Dr. Surupa Susan Kurien,

1D Avenue Regency,

Adjacent St. Mary's Church, Pattom P.O.,

Thiruvananthapuram-695004, Kerala.

E-mail: surupasusan@gmail.com

DOI: $10.14260 /$ jemds $/ 2017 / 1009$
This study was undertaken to describe the various lesions that occur in posterior fossa pertaining to their incidence, age and sex distribution, location and to evaluate the extent of agreement between the clinico-radiological and histopathology diagnosis.

\section{MATERIALS AND METHODS}

The study was a descriptive study conducted in the Department of Pathology, Medical College, Trivandrum. A retrospective analysis of biopsy specimens from posterior fossa lesions received in the Department of Pathology over a 3-year period was done. The data collected included age, sex, site of lesion, clinical, radiological and histopathological diagnosis. A total of 75 biopsy specimens were studied and the clinical data was correlated. Histopathology diagnosis was used as the gold standard. Sensitivity, specificity and agreement using kappa statistics was calculated to correlate clinical and histopathological diagnosis.

\section{RESULTS}

Out of the 75 specimens received 55 were neoplastic lesions, while 11 were non-neoplastic (Fig. 1 - 3). The neoplastic lesions included pilocytic astrocytoma (6 cases), diffuse astrocytoma (4 cases), glioblastoma multiforme (3 cases), ependymoma (3 cases), medulloblastoma (8 cases), 
Schwannoma (15 cases), meningioma (4 cases), haemangioblastoma (5 cases), metastases (7 cases). Nonneoplastic lesions diagnosed were 8 cases of abscess and 3 cystic lesions diagnosed as arachnoid cyst. Among the neoplastic lesions the most commonly encountered was Schwannoma (20\%) followed by medulloblastoma (11\%). Most common neoplastic lesion in children was medulloblastoma; 9 biopsies were non-diagnostic due to inadequate material. Of the total 75 cases, 8 were recurrent neoplasms - pilocytic astrocytoma (2), ependymoma (2), schwannoma (2), medulloblastoma (1) and haemangioblastoma (1) (Table 1).

\begin{tabular}{|c|c|c|}
\hline Name of the Lesions & Number of Patients & Percentage \\
\hline Pilocytic astrocytoma & 6 & 8 \\
\hline Diffuse astrocytoma & 4 & 5.33 \\
\hline Glioblastoma & 3 & 4 \\
\hline Ependymoma & 3 & 4 \\
\hline Medulloblastoma & 8 & 10.7 \\
\hline Schwannoma & 15 & 20 \\
\hline Meningioma & 4 & 5.3 \\
\hline Haemangioblastoma & 5 & 6.7 \\
\hline Metastasis & 7 & 9.3 \\
\hline Abscess & 8 & 10.7 \\
\hline Cystic lesions & 3 & 4 \\
\hline Inconclusive & 9 & 12 \\
\hline Total & 75 & 100 \\
\hline \multicolumn{3}{|c|}{ Table 1. Histopathological Diagnosis } \\
\hline
\end{tabular}

Regarding the age distribution, majority of the lesions were seen in adults in the $5^{\text {th }}$ decade $(20 \%)$. Children accounted for $16 \%$ of the cases. The distribution among males and females were $57 \%$ and $43 \%$ respectively with the exception of meningioma and haemangioblastoma that showed a female preponderance.

The most frequent clinical presentations were headache (67\%) and vomiting (55\%). Cerebellar signs (28\%) and papilloedema (12\%) were noted in pilocytic astrocytoma, medulloblastoma and haemangioblastoma; 12 of the 15 cases of Schwannoma presented with vertigo. Non-neoplastic lesions like cerebellar abscess manifested with fever, drowsiness and majority gave history of untreated chronic suppurative otitis media.

The most common radiological findings reported were heterogeneous attenuation and cystic enhancement; $62 \%$ of medulloblastoma presented as hyperdense lesions. Cyst with mural nodule was the common presentation in $66.67 \%$ cases of Pilocytic astrocytoma; 10 out of 15 cases of schwannoma were heterogeneous.

Sites of lesion involvement in posterior fossa in the descending order of frequency were the followingCerebellum in $70 \%$ followed by CP angle in $23 \%$, $4^{\text {th }}$ ventricle in $4 \%$ and brain stem in $3 \%$.

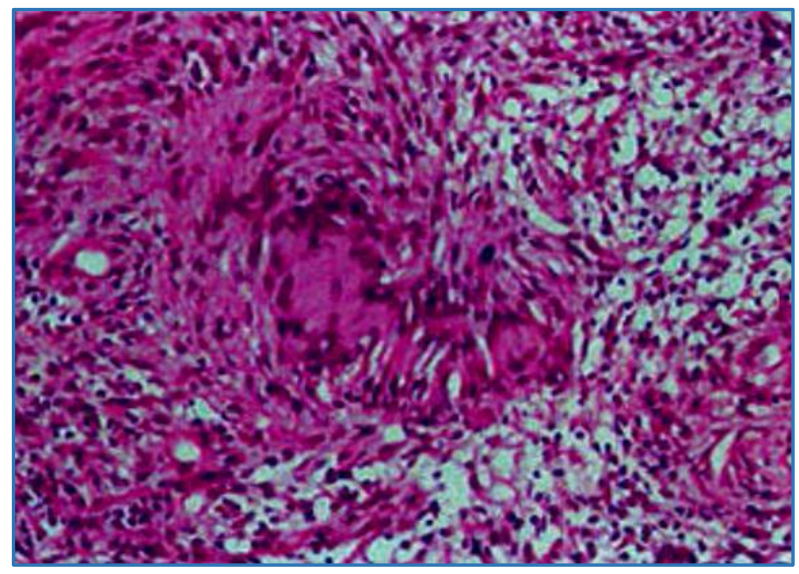

Figure 1. Schwannoma (40X)

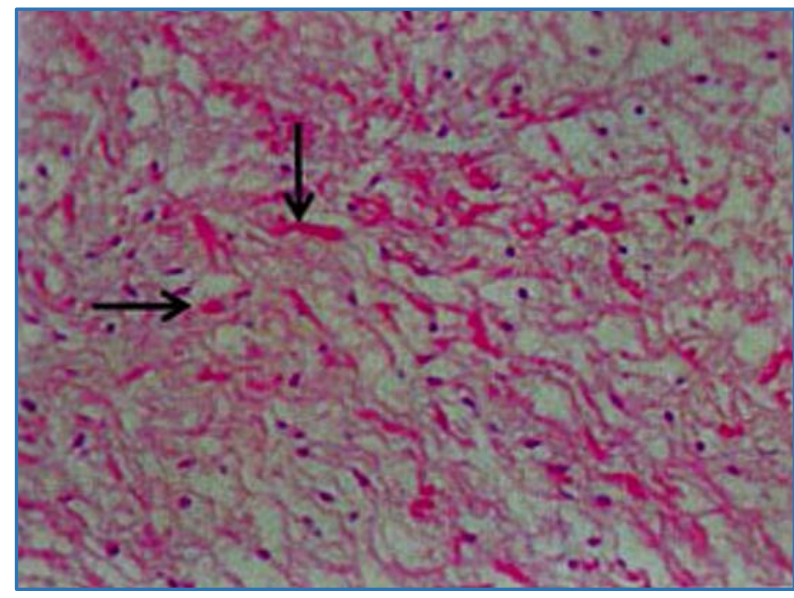

Figure 2. Pilocytic Astrocytoma (40X)

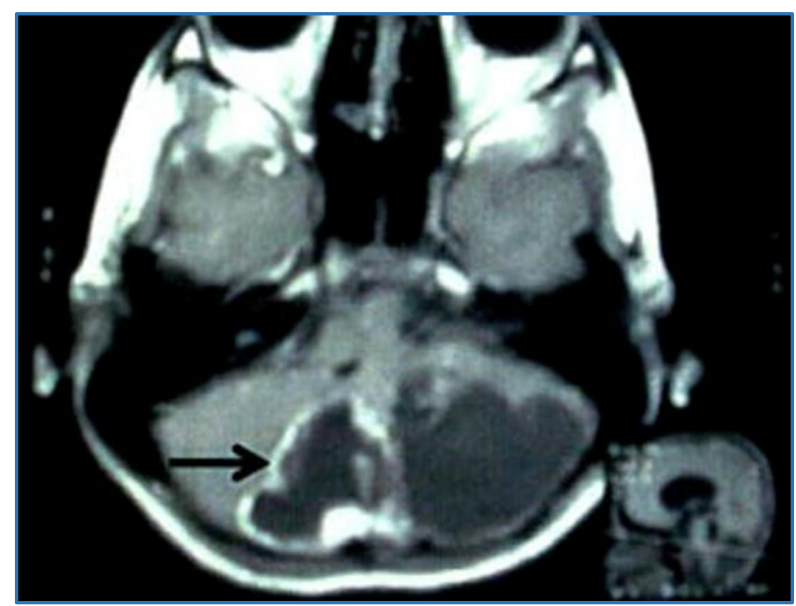

Figure 3. CT Post Contrast Study of Pilocytic Astrocytomaa Well-Defined Cystic Septate Mass Lesion with Irregular Thickened Wall shows Contrast Enhancement

In our study, agreement between the clinico-radiological and pathologic diagnosis was noted in $64 \%$ of the cases. The highest agreement was noted for glioblastoma multiforme, Schwannoma and arachnoid cyst which showed perfect agreement with $100 \%$ sensitivity. Cases of pilocytic astrocytoma showed the least agreement with a sensitivity of 33.33\% (Table 2). 


\begin{tabular}{|c|c|c|c|}
\hline Diagnosis & Sensitivity & Specificity & $\begin{array}{l}\text { Agreement } \\
\text { (Kappa) }\end{array}$ \\
\hline Pilocytic astrocytoma & $33.33 \%$ & $96.67 \%$ & 0.353 \\
\hline Diffuse astrocytoma & $50 \%$ & $93.55 \%$ & 0.353 \\
\hline $\begin{array}{l}\text { Glioblastoma } \\
\text { multiforme }\end{array}$ & $100 \%$ & $100 \%$ & 1 \\
\hline Ependymoma & $66.67 \%$ & $95.24 \%$ & 0.47 \\
\hline Medulloblastoma & $62.5 \%$ & $94.83 \%$ & 0.573 \\
\hline Schwannoma & $100 \%$ & $100 \%$ & 1 \\
\hline Meningioma & $75 \%$ & $98.39 \%$ & 0.734 \\
\hline Haemangioblastoma & $80 \%$ & $100 \%$ & 0.881 \\
\hline Metastasis & $57.14 \%$ & $94.92 \%$ & 0.521 \\
\hline Abscess & $62.5 \%$ & $98.28 \%$ & 0.681 \\
\hline Cystic lesion & $100 \%$ & $100 \%$ & 1 \\
\hline \multicolumn{4}{|c|}{$\begin{array}{c}\text { Table 2. Agreement between Clinical } \\
\text { and Histopathological Diagnosis }\end{array}$} \\
\hline
\end{tabular}

\section{DISCUSSION}

We received a total of 75 cases of posterior fossa lesions in the 3-year period. Most of the lesions occurred in the age group between 50 and 59 years (20\%) followed by 0 and 9 years (16\%). The male-to-female ratio observed was 1.33: 1 with a female preponderance seen in cases of meningioma and haemangioblastoma.

The most frequent clinical presentations were headache (67\%) and vomiting (55\%), which reflects raised intracranial pressure. In study by Hari et $\mathrm{al}^{2}$ raised intracranial pressure was the most common presentation seen in $92.3 \%$ cases. Cerebellar signs (28\%) and papilloedema (12\%) were noted in pilocytic astrocytoma, medulloblastoma and haemangioblastoma. Patients with cerebellar abscess had history of fever and drowsiness. Vertigo, tinnitus, hearing loss and cranial nerve palsies were seen in patients with Schwannoma.

In the study, neoplastic lesions were more common than non-neoplastic lesions. The non-neoplastic lesions encountered were cerebellar abscess and arachnoid cyst. Six out of eight patients with cerebellar abscess had history of fever, drowsiness and chronic suppurative otitis media similar to the findings of Miura et al. ${ }^{3}$

The arachnoid cyst was seen in the age group $30-35$ years with all the three cases being situated in the cerebellum. In a study by Galarza et al, the posterior fossa arachnoid cysts were located at the vermis-cisterna magna $(n=4)$, the cerebellar hemispheres $(n=2)$, the cerebellopontine angle $(n=3)$ and the quadrigeminal cistern $(n=1) .4$

Among the neoplastic lesions, the most commonly encountered was Schwannoma (20\%) followed by medulloblastoma. Consistent with the findings in series by Kalyani et $\mathrm{al}^{5}$ the most common tumour seen in adults in our study was Schwannoma, while the most common among children was medulloblastoma. Tabatabaei et al had also reported medulloblastoma as the commonest tumour in children in posterior fossa with an incidence of $42.8 \%, 6$ while Hari et al reported pilocytic astrocytoma as the commonest tumour in children in their series.

The age group affected in Schwannoma was in the $3^{\text {rd }}$ to $6^{\text {th }}$ decade with a male-to-female ratio of $1: 1.14$. This is comparable to the findings of Casadei et al, 7 which showed peak incidence in $4^{\text {th }}$ to $6^{\text {th }}$ decade and male-to-female ratio of 1: 2 . Tinnitus, hearing loss and cranial nerve palsies were the most frequent symptoms.

All the cases of meningioma were seen exclusively in females in our study with the patients falling into the age group of 35 to 70 years. Helseth et al ${ }^{8}$ observed the occurrence of meningioma predominantly in females and in the middle decade.

There were a total of 13 cases of astrocytomas, of which 6 were pilocytic astrocytomas, 4 were diffuse astrocytomas and 3 were glioblastoma multiforme. Pilocytic astrocytoma was seen in the age group of 4 to 20 years, similar to the findings of Garcia et al $^{9}$ of 1 to 19 years. The incidence in children in our study was found to be $21.42 \%$. Radiologically, $66.67 \%$ cases showed cyst with solid mural nodules and $33.33 \%$ cases were recurrent lesions.

The incidence of ependymoma was $14.29 \%$ with a maleto-female ratio of 2: 1 . Out of the total 3 cases, 1 was a recurrent case of anaplastic ependymoma. The site of lesion was $4^{\text {th }}$ ventricle in all the cases $(100 \%)$ compared to $60 \%$ in the series of Schiffer et al. ${ }^{10}$

Medulloblastoma was noted in a wide range of age group between 2 and 37 years with $75 \%$ of the cases falling below the age of 10 years. It was also the commonest neoplastic lesion in children in our series.

There were 5 cases of haemangioblastoma, in which $60 \%$ of the tumours occurred in females. $40 \%$ of the patients presented radiologically as cysts with mural nodule. Metastatic tumours in cerebellum are uncommon according to Garg et al. We got 7 cases of metastatic tumours of posterior cranial fossa.

In our study, agreement between the clinico-radiological and pathologic diagnosis was noted in $64 \%$ of the cases. The highest correlation was noted for glioblastoma multiforme, Schwannoma and arachnoid cyst which showed 100\% agreement. Cases of pilocytic astrocytoma showed the least agreement.

\section{CONCLUSION}

Posterior fossa lesions form a high percentage of central nervous system pathologies for which excision is performed. They affect all age groups, especially paediatric age group with a male predominance. Clinicopathological correlation and grading are significant as many of the tumours require radiotherapy and chemotherapy in addition to surgical excision. Strict followup is needed in many of the posterior cranial fossa tumours especially ependymoma, haemangioblastoma and pilocytic astrocytoma as they have tendency to recur frequently.

\section{REFERENCES}

[1] Snell RS. Clinical anatomy for medical students. $6^{\text {th }}$ edn. Published by Lipincott. Williams and Wilkins 2003.

[2] Hari SP, Jyothi JSA, Thatipamula M. Study of posterior fossa tumors by high resolution MRI. J Evid Based Med Healthc 2016;3(6):197-203.

[3] Miura MS, Krumennauer RC, José F, et al. Intracranial complications of chronic suppurative otitis media in children. Rev Bras Otorrinolaringol 2005;71(5):63943. 
[4] Galarza M, López-Guerrero AL, Martínez-Lage JF. Posterior fossa arachnoid cysts and cerebellar tonsillar descent: short review. Neurosurg Rev 2010;33(3):305-14.

[5] Kalyani D, Rajyalakshmi S, Kumar OS. Clinicopathological study of posterior fossa intracranial lesions. J Med Allied Sci 2014;4(2):62-8.

[6] Tabatabaei SM, Seddighi A, Seddighi AS. Posterior fossa tumor in children. Iran J Child Neurol 2012;6(2):19-24.

[7] Casadei GP, Komori T, Scheithauer BW, et al. Intracranial parenchymal schwannoma a clinicopathological and neuroimaging study of nine case. Journal of Neurosurgery 1993;79(2):217-22.
[8] Helseth A, Mork SJ, Johansen A, et al. Neoplasms of the central nervous system in Norway. A populationbased epidemiological study of meningiomas. APMIS 1989;97(7):646-54.

[9] Garcia DM, Latifi HR, Simpson JR, et al. Astrocytomas of the cerebellum in children. J Neurosurg 1989;71(5 Pt 1):661-4.

[10] Schiffer D, Chiò A, Giordana MT, et al. Histologic prognostic factors in ependymoma. Childs Nerv Syst 1991;7(4):177-82. 